\title{
Refocusing on the Success Enabling Factors in Mergers and Acquisitions
}

\author{
Anthony Okafor, PhD \\ College of Management and Technology, Walden University, USA
}

Doi:10.19044/esj.2019.v15n16p172 URL:http://dx.doi.org/10.19044/esj.2019.v15n16p172

\begin{abstract}
Mergers and acquisitions have continued to serve as a primary financing tool undertaken by organizations to achieve corporate objectives. Despite the increased popularity of the mergers and acquisitions phenomenon, determining acceptable metrics for identifying successful mergers and acquisitions continue to pose challenges to investors, financial analysts and other stakeholders involved with mergers and acquisitions. Mergers and acquisitions activities have presented mixed outcomes to different organizations with high failure rates recorded in some and less-significant successes reported in others. Consequently, understanding acceptable metrics for determining a successful merger or acquisition becomes paramount given the challenges experienced by players in that industry. Therefore, a thorough review of the literature is made in this study to identify factors that improve the chances of mergers and acquisitions success. The unique features of successful and unsuccessful mergers and acquisitions are itemized to provide a premise for assessing and evaluating the essential characteristics that make mergers and acquisitions successful. The importance of due diligence, low acquisition purchase premiums, and related business acquisitions in the mergers and acquisitions process were fully explicated. Low acquisition purchase premiums, timing of mergers and acquisitions and related business acquisitions were found to tremendously enhance the success of mergers and acquisitions.
\end{abstract}

Keywords: Mergers and acquisitions, Acquisition purchase premiums, Due diligence

\section{Introduction}

In the past five decades, scholars have made significant literary interventions to the mergers and acquisitions phenomenon. Mergers and acquisitions (M\&A) present a huge interest for financial analysts, investors as well as academics, including the financial, strategic, cultural, operational and 
behavioral aspects of M\&A (Cartwright \& Schoenberg, 2006). Mergers and acquisitions has been identified as means for an organization to achieve growth, diversity, and profitability and this explains the increased level of M\&A activities experienced in the last two decades (Ikhwan \& Haeruddin, 2017). Increasingly, organizations have taken to M\&A to achieve corporate objectives, increase market share, and diversify their operations (Friedman et al., 2016; Schmidt, 2015).

Notwithstanding the increased popularity of M\&A, the phenomenon has presented different outcomes to different organizations that have either merged or acquired another firm. While the increased volume is widely observable, the high rate of failure is also visible (Houwers, 2016). Analysts put the abysmal failure rate of M\&A at 70\%-90\% (Martin, 2016). Prominent among the highly successful M\&A were Glaxo/SmithKline in pharmaceuticals, Vodafone/Mannesmann in telecommunications, and Royal Dutch Petroleum/Shell Transport \& Trading in oil and petroleum (Hoang \& Lapumnuaypon, 2007). The experience was not the same for Daimler-Benz's acquisition of Chrysler which cost Daimler-Benz a record \$30bn loss (French, 2018).

Despite the enormous research about M\&A, there appears to be a gap in literature that accentuates the cause of $M \& A$ failure and the unique features about successful M\&A. This has increased calls by scholars and practitioners involved with M\&A to identify the essential elements that make successful M\&A standout. Consequently, in this study, attempts will be made to critically review the characteristics of successful M\&A to guide organizations seeking to enter the M\&A market.

\section{Purpose of study}

The purpose of this study is to identify and critically evaluate the unique features of successful mergers and acquisitions. Also, I highlight the typical M\&A process and how acquiring firms select their targets. Attempts are made to discuss the challenges of M\&A and ways to enhance the selection process to improve the success rate of M\&A transactions.

\section{Literature Review}

\section{Understanding Mergers and Acquisitions}

Literature is replete with different scholarly interventions and definitions of M\&A. For this study, I align with Ross, Westerfield and Jaffe's (2010) explanation that mergers and acquisitions is a strategic expansion activity to transfer the control of a firm from one set of shareholders to another. Corporate restructuring is a fundamental strategy usually achieved through M\&A to achieve organizational growth and changing the ownership structure of firms (Garzella \& Fiorentino, 2014). Ikhwan and Haeruddin (2017) also 
identified M\&A as a means of achieving organizational growth, diversity, and profitability. Besides gaining control, growth or achieving profitability, organizations also carry out M\&A to increase managerial synergy and technical know-how from the target firms (Matsusaka, 1993).

The two terms "merger" and "acquisition" have been used interchangeably but in reality are quite distinct. Acquisition involves a larger company acquiring a smaller or distressed company by taking over the board and management of the target firm (Clark \& Mills, 2013). An acquisition is achieved when the acquirer takes more than $50 \%$ control in the acquiree's equity to gain managerial influence which sometimes comes without agreement (Jagersma, 2005; Piesse et al., 2013). Merger involves the combination of two or more firms to form a new legal entity to achieve mutually beneficial strategic alliances (Ciobanu, 2015; Jagersma, 2005). Therefore, an organization might outrightly acquire another firm and assume ownership, which is the most common type of deal nowadays or merging with another firm where ownership and control are shared (Clark \& Mills, 2013). Thus, both in reality and economic implication, both terms are different, however, establishing the differences between the two terms falls outside the scope of this study.

\section{Historical Perspective to Mergers and Acquisitions}

Mergers and acquisitions have evolved over the years through various patterns generally known as waves or cycles (Clark \& Mills, 2013). The first documented wave of M\&A occurred in the U.S in 1891 with the intention of establishing monopolies, determining prices and a means of eliminating competitors rather than leveraging the process to achieve economies of scale (Becketti, 1986; Lamoreaux, 1985). The second wave started in the 1920s with developing economies of scale as the primary consideration (Martynova \& Renneboog, 2008). The second M\&A wave led to the breaking of monopolies and resulted in oligopolies that took control of their respective industries (Stigler, 1950). Shleifer and Vishny (1991) reported that the third wave of M\&A occurred as a result of antitrust laws enacted in the U.S in 1960 to protect consumers from the predatory tendencies of businesses and the general quest for diversification. Organizations exploited M\&A as a diversification strategy by entering new markets and establishing independent businesses to increase value and smoothen their cash flows (Copeland, Weston, \& Kuldeep, 2004).

The fourth M\&A wave was triggered by globalization in the 1980s; acquiring companies had access to increased capital flows which provided opportunities for leverage buyouts (Jewoo \& Tianshu, 2014). Changes in the antitrust laws supported horizontal M\&A, and corporate restructuring enabled companies to refocus and through M\&A (Andrade, Mitchell, \& Stafford, 
2001; Bhide, 1990). The fourth M\&A wave in the U.S was typified by dramatic takeovers in which some of the largest companies became a subject of acquisition such as Gulf Oil and Kraft (Cordeiro, 2014). The fifth M\&A wave which occurred between 1993 and 2007 was greater in size and geographically dispersed compared to the previous M\&A waves (Jewoo \& Tianshu, 2014). In 2000 alone, a record number of 8505 deals were reported and valued at over $\$ 1.7$ trillion (Sikora, 2001).

The fifth wave was supported by European and Asian firms especially of Chinese origin seeking investment opportunities through M\&A (Martynova \& Renneboog, 2008). This period was also the time of the dot-com and subprime derivatives bubble in the U.S which increased liquidity within the system (Clark \& Mills, 2013). However, this period saw a significant reduction in the amount of premiums paid by acquirers compared to the previous ones as firms became less optimistic of achieving the desired synergy (Alexandridis, Mavrovitis, \& Travlos, 2012). Nonetheless, acquisition volumes and value continue to soar. In 2016, a record \$3.7trn M\&A activities were completed with energy, power and high-tech sectors being the most targeted (Thomson Reuters, 2017).

\section{Type of Mergers and Acquisitions}

Typically, M\&A are classified into two groups namely conglomerates and non-conglomerates (horizontal and vertical) mergers (Yagil, 1996). A conglomerate M\&A is essentially a diversification strategy undertaken by two firms working at unrelated industries seeking to diversify investment and achieve economies of scale (Gaughan, 2002). A typical example of this type of M\&A was seen in the acquisition of the American Broadcasting Company by Walt Disney.

Horizontal M\&A occurs when the two companies involved are from the same industry (Becketti, 1986). Organizations undertake horizontal M\&A to reduce operating cost, increase market share, share complementary skills and resources, and through that seek business opportunities in a new market (Westbrock, 2004). Globalization is one major factor that has increased horizontal M\&A activities as foreign firms seeking to enter into new markets form a strategic alliance with existing players in the industry (Beena, 2014). A highly celebrated example of this form of consolidation occurred in the pharmaceutical industry which was the merger between Glaxo Wellcome and SmithKline Beecham in 1999, now referred to as GlaxoSmithKline (Abbott, 2000).

Vertical M\&A occurs when one of the two companies involved operates in the downstream sector of the industry, and the other party operates in the upstream of the same industry either as buyers or suppliers in the value chain (Chemla \& Chemla, 2003). The overarching intention is usually to 
reduce dependence on other firms, achieve economies of scale and to reduce overhead cost. A typical example of this type of consolidation was seen in the acquisition of Nigerian Soft Drinks Company by Nigeria Bottling Company (Olowoniyi \& Ojenike, 2012).

\section{Merger and Acquisition Process}

A typical M\&A follows five major processes before the deal is closed. Ruess and Voelpel (2012) identified the five major processes to include identification of the target, making acquisition or merger decision, deal completion, integration and making post-acquisition or post-merger assessment. Within these processes, other activities could take place such as searching and screening, risk assessment, determining the right valuation; however, they all fall within the generic M\&A process discussed below.

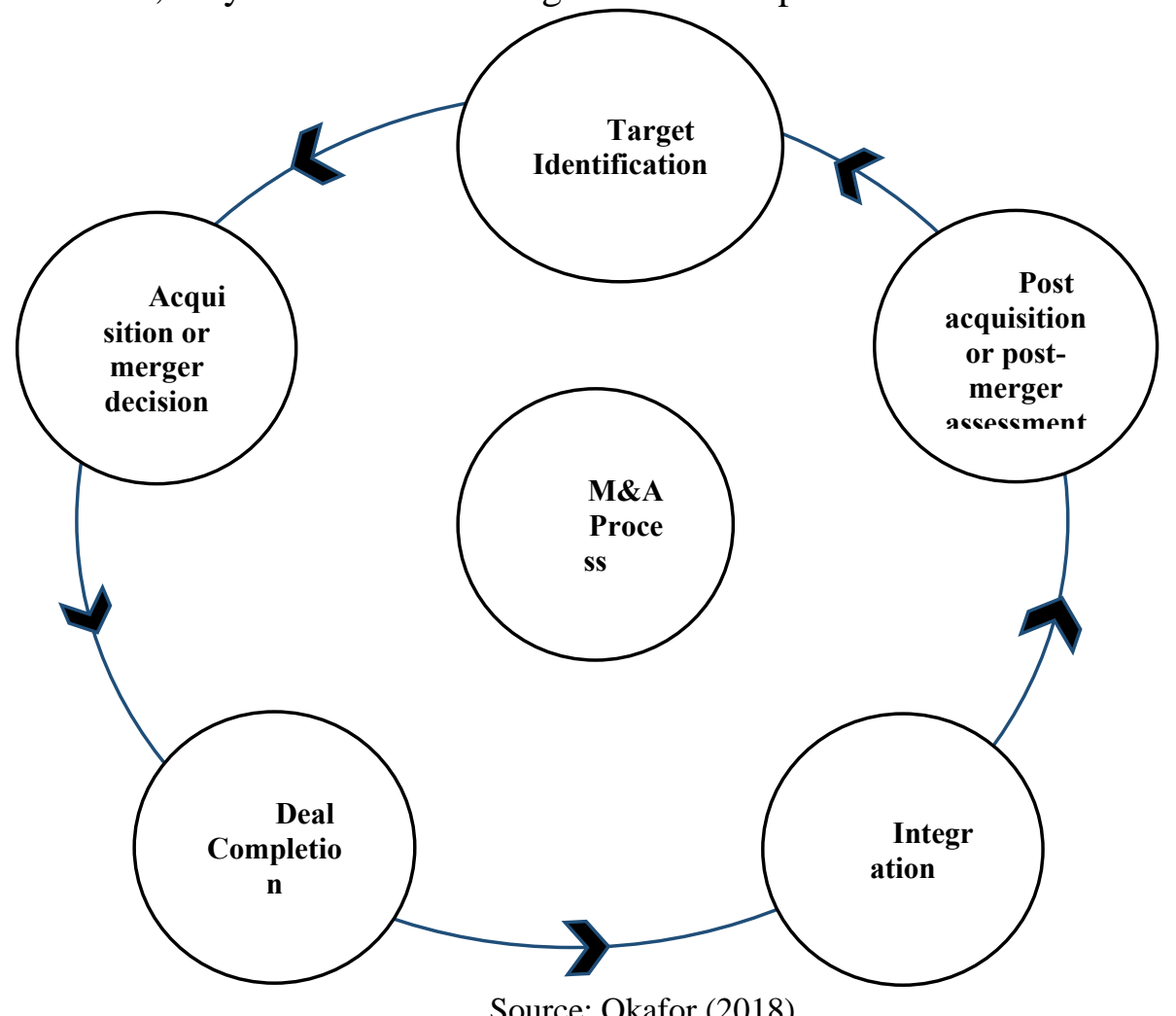

Figure 1: Typical M\&A Process

The process of consummating M\&A is often administered by an investment bank serving as an intermediary between the two parties, reviewing and completing all relevant documentation (Okafor, 2018). The M\&A process begins as shown in figure 1 by identifying the target firm. At this stage, the acquiring firm, which is often the initiator and on the buy side 
of the deal performs a preliminary screening and due diligence to ascertain the health of the company. The target firm is often on the sell side. The next phase is the decision-making stage where a formal presentation stating the intentions of the acquirer is made to the target firm through an expression of interest letter.

The third stage is the deal completion phase where the two parties come together through their representative to agree on the deal price and several issues related to the transaction. If the terms are agreeable, a deal is struck, and a decision is made on the payment, either by cash or through share exchange and whether part of the amount will be deferred (Sankar, 2018). The fourth phase is where the acquired company is integrated into the business of the acquirer or operated as a standalone company (Benson \& Shippy, 2013). The final phase involves an assessment of the whole exercise which could be done at any time following the deal completion.

\section{Motives for Mergers and Acquisitions}

Firms undertake M\&A for many reasons usually determined by their strategic objectives. One prominent reason why companies make M\&A is to achieve synergy (Okafor, 2018). Synergy can be defined as the present value of the net additional cash flow generated by a combination of two companies that could not have been generated by either of the two companies on its own (Ficery, Tom \&, Pursche, 2007; Pamplona \& Junio, 2013). The resulting impact of the union is such that $1+1=3$, the difference being the value created because of the combination of the two companies (Malik et al., 2014). Empirical evidence has shown that the combined value of the two firms is usually higher than the sum of the two companies before securing M\&A (Junior, Pamplona, \& Francisco-da-Silva, 2013). Achieving revenue, cost and financial synergies tend to be the major consideration for most M\&A. Revenue and cost synergies can be realized through economies of scale and scope in production or distribution while financial synergies can come through diversification (Vretenar, Sokolic \& Mrak, 2017).

Corporate restructuring is another reason identified as the motive for M\&A. Corporate restructuring is a fundamental strategy for undertaking M\&A to reposition the affairs of the organization to achieve growth, market share, and profitability (Garzella \& Fiorentino, 2014). An example of this was seen in the acquisition of Oceanic Bank by Ecobank Transnational Incorporation (ETI) in Nigeria in 2011. Oceanic Bank was acquired to boost the retail expansion of ETI and give it some scale in the industry (Aderinokun \& Chima, 2011). Since Oceanic Bank is a strong competitor, the acquirer was able to leverage the operations and the branch network of the acquiree to achieve overall growth and profitability. Large banks also acquire smaller but 
efficient banks with more diversified income to give the acquirer economies of scope (Marques-Ibanez \& Altunbas, 2004).

Diversification is another motive for $M \& A$. The diversification motive is rooted in the modern portfolio theory which assumes that a firm can reach its optimal risk level if it invests in uncorrelated instruments (Motis, 2007). Diversification assists organizations seeking to reduce company-specific risks to diversify their income sources and operations which is a financial strategy. Verma and Sharma (2014) identified M\&A as an entry strategy into a target industry which facilitates diversification and corporate restructuring. Diversification also enables resource reallocation through the transfer of funds from areas of surplus to areas where the funds can be effectively utilized (Okafor, 2018). A typical example of the diversification strategy can be seen in the activities of Old Mutual, a U.K company established in the 19th century with specialties in asset management, unit trusts, and life insurance business (Brearley, 2013).

Other reasons for $\mathrm{M} \& \mathrm{~A}$ include increasing the efficiency of management, acquire technical competency, and improve research and development capability (Smirnova, 2014). There could also be some political consideration such as gaining the support of government (Smirnova, 2014). A firm might make acquisition principally to sell complementary products similar to that of the acquired firm such as a bank selling complementary products of a stockbroking firm (Arora \& Kumar, 2012).

\section{Determining a Successful M\&A}

Different attempts have been made in the last two decades to define successful M\&A. Hogarty (1970) described a successful M\&A as one that increases the present value of the future returns accruing to the acquiring firm's shareholder. This means that M\&A needs to improve the interest of the owners of the acquiring firm which is closely linked to the strategic objective of the organization and should be established before embarking on the deal. This view is supported by Ghaur (2017) who posits that M\&A success is determined by shareholder's assessment of whether the deal serves their interest which affirms the primacy of the shareholders in deciding whether an M\&A is successful or not.

In another perspective, Clark and Mills (2013) affirmed that the success of M\&A was directly linked with acquisition purchase premium (APP) paid by the acquirer (p.342). If the APP is lower than the expected realizable synergy, that is, if the value of the combined firm is higher than the individual value of the two firms before the deal, the M\&A could be said to be successful. This is based on the logic that for an asset to be of economic value to the acquiring firm, the amount paid for that asset should be lower than the economic value derivable (Cording, Christmann \& Bourgeois, 2002). The 
view that M\&A create economic value has been supported by (Seth, 1990; Singh \& Montgomery, 1987). However, researchers are of the view that the shareholders of the firm acquired benefit more from the new wealth created (Datta, Pinches \& Narayanan, 1992; Sirower, 1997).

Mainly, there are four major approaches to measuring the success of M\&As. The first being event studies is an analytical tool used to assess the impact of an event and other changes in the M\&A environment on the firm's value when M\&A announcement is made (Clark \& Mills, 2013). The event study method allows for an assessment of the stock prices of both the acquiring and acquired firm after the announcement. The second approach is the value gap estimation in which an estimate of the premium versus the expected synergy is provided to assure shareholders that the deal was worth it and there has not been an issue of an overpayment (Clark \& Mills, 2013). The acquirer's total shareholder return is another means for assessing the failure or success of M\&A. This approach is an accounting-based process that is used to guide shareholders evaluation of the success of the M\&A based on the firm's new cost of capital (Clark \& Mills, 2013). The fourth method is the Incremental Value Effect that uses the discounted cash flow (DCF) of the company postM\&A to assess whether the deal is worth it or not (Clark \& Mills, 2013).

For this study, I align with Hogarty's (1970) definition of what constitutes a successful M\&A. Hogarty's (1970) interpretation is preferred because it considers the importance of time in assessing whether the deal is successful or not. A considerable amount of time is required for the full impact of the combination to become visible (Cording, Christmann \& Bourgeois, 2002). This perhaps explains why only one-third of acquirers experience an appreciable increase in share price post-M\&A announcement (Sirower, 1997). For instance, in Nigeria, when Access Bank acquired Intercontinental Bank in 2011, the share price of Access Bank was unmoved as investors took time to digest the potential benefit that will accrue to the acquirer; integration was not also completed until two years after acquisition. However, post-consolidation, Access Bank reported its highest PAT and dividend in 2013 (Access Bank, 2013).

\section{Characteristics of Successful M\&A}

Advisory firms usually identify a successful M\&A based on the successful completion of the acquisition process while the acquirers view successful M\&A based on the additional value the acquisition adds to acquirers (Clark \& Mills, 2013). The essential features that determine successful M\&A are discussed as follows: 


\section{Acquisition Purchase Premium (APP)}

Lower acquisition purchase premiums are unique features of successful M\&A deals. Acquisition premium is the amount paid for a target that exceeds its pre-acquisition market value (Hitt et al., 2002). M\&A is a competitive process in which the highest bidder clears the bid which is usually between $20 \%$ and $50 \%$ of the preannouncement value of the target firm's equity (Laamanen, 2007). Scholars are united on the fact that APP plays a crucial role in determining whether an M\&A becomes successful or not (Clark \& Mills, 2013; Cording, Christmann \& Bourgeois, 2002). Clark and Mills (2013) observed that a lower APP enhances the chance of synergy realization and a higher APP increases the level of losses on the acquisition.

Therefore, a unique quality of any successful acquisition lies in the strategy adopted in arriving at the purchase premium such that the premium paid is lower compared to the expected synergy (Rock, 1986). This is particularly important considering that premiums are paid up-front while uncertainty pervades the expected synergy (Hitt et al., 2002). Also, because APP determines the final bid price, a higher bid price is already a precursor to M\&A failure. An instance of a high APP was seen in the Time Warner and AOL deal which failed to live up to expectation because of the excessive bid price for AOL causing the share price of Time Warner to plummet (Covin, 2003). To avoid paying an exorbitant premium, Sirower (1997) suggested that the risk of generating synergistic effects should be built into the discount rate used for determining the present value of the expected synergies.

\section{Due Diligence}

A thorough understanding of the target company's operations is key to success, and this involves performing due diligence on the target firm. Due diligence in M\&A goes beyond having a cursory glance at the target firm's financial statements to include assessing a raft of business, intellectual and other material information about the company (Ceil, 2013). A thorough analysis of all financial metrics relating to the company is vital to achieving a successful M\&A because due diligence provides further insights into the firm's projected growth, their assumptions and allows the acquirer draw up necessary strategies to support such plans. In addition to analyzing the financial metrics, a holistic review of all existing contracts and commitments with other parties such as revenue sharing and settlement agreements is necessary (French, 2018).

Due diligence also gives further understanding of the target firm's corporate culture, customer base and competition (Denison \& Ko, 2016). Conflicting culture accounts for $91 \%$ of M\&A failures (French, 2018), so part of due diligence will be to ensure that the target firm's organizational culture is not at variance with the acquirer's culture which is essential to achieving 
successful M\&A. One of the most documented M\&A failures that arose as a result of a misfit in corporate culture was the merger between Daimler-Benz and Chrysler (French, 2018). The \$35bn acquisition of Nextel Communications by Sprint in 2005 was another example of how not understanding the culture, customer base and competition of the target firm could lead to significant losses (French, 2018).

Differences on how customers should be treated ensued after the transaction and this led top senior executives and other staff to exit the company to another competitor AT\&T. The result was a reduction in customer loyalty and patronage, and this led to $\$ 30 \mathrm{bn}$ impairment to goodwill which was written-off in 2008 (French, 2018). Therefore, most pitfalls in M\&A could be avoided if identified beforehand which explains why most successful M\&A benefit from having thorough due diligence on the target company.

\section{Timing of $\mathbf{M \& A}$}

Another unique characteristic of successful M\&A is the appropriate timing of the deal during the merger wave cycle, also referred to as early positioning (Iankova, 2014). Early positioning increases the chance of success in M\&A because acquirers who position early during the M\&A cycle can buy at a lower price which creates a unique combination of inimitable synergies (Lieberman \& Montgomery, 1988). Conversely, when the business cycle is hot, the competition is usually high and increases the temptation to outbid other parties leading to overpayment.

Besides, searching for valuable companies to acquire during a recession is also linked to timing and essential to achieving successful M\&A. During a recession, the market is depressed, and stock prices are significantly lower presenting opportunities for acquirers to make cheap acquisitions during a recession. For instance, during the economic downturn in 2008, Roche Holding Switzerland acquired Genentech Inc for $\$ 43.7 \mathrm{bn}$, and Bank of America took over Merrill Lynch for \$48.8bn in what analysts consider as opportunistic acquisitions (Grave, Vardiabasis \& Yavas, 2012). This also involves taking advantage of prevailing market situations in foreign economies to make cross-border acquisitions for organizations in pursuit of diversification.

\section{Acquired Experience}

In addition to paying an optimal premium and identifying the appropriate timing, an essential feature of most successful M\&A is the experience of the acquiring organization. In their study on learning theory, Haleblian and Finkelstein (1999) contend that a U-shaped relationship exists between previous experience and M\&A success. They further argued that the similarity between the new target and the previously acquired firm increases 
the chance of success post-acquisition. Unum's \$5bn acquisition of Provident Insurance Company in 1999 is a typical example of how experience positively impacts M\&A success following the company's previous acquisitions of U.K's NELPHI in 1990 and the Colonial Life in 1993 (Carroll \& Mui, 2009). The learning theory view has been further expanded to include experience in heterogeneous acquisitions. Beckman and Haunschild (2002) concluded that acquirers with prior experience in heterogeneous acquisitions tend to pay lower APP thereby improving the performance of the firm post-acquisition.

\section{Related Business Acquisitions}

Related business acquisition has been described as one of the unique determinants of successful M\&A, and it increases the possibility of creating synergistic gains (Jewoo \& Tianshu, 2014). Ikhwan and Haeruddin (2017) observed that related business acquisitions also reduce integration challenges which are one of the primary reasons why most M\&A fail. Integrating a new company which is entirely unrelated to the acquirer's business requires a steep learning curve and could take time to accomplish.

A typical example of how related business acquisitions increase M\&A success could be seen in the activities of Chase Manhattan Corporation (Chase Bank) when it acquired J.P. Morgan \& Company in 2000 for \$30.9bn (McGeehan \& Sorkin, 2000). Before this acquisition, Chase Bank had made similar acquisitions such as Chemical Bank and Manufacturers Hanover and the acquisition of some smaller investment banking outlets like Hambrecht \& Quist in 1999 to strengthen its underwriting business (McGeehan \& Sorkin, 2000).

The acquisition of J.P Morgan was successful because Chase Bank was able to integrate and consolidate the acquisition faster than it would have if the acquired firm operated in another industry because of its experience in managing similar businesses. Similarly, the M\&A transactions between Shell and Royal Dutch Petroleum, Disney and Pixar, and Exxon and Mobil are good examples of related business acquisitions. Besides related business acquisitions, Refsnes (2012) have also argued that the success rate of mergers increases if the two parties have similar organizational structures and strategies meaning that there will be fewer changes post-merger thereby improving integration and realization of the companies' objectives.

\section{Communication}

Communication is another essential but often overlooked factor that enhances M\&A success. Scholars are united that effective organizational communication during and post-M\&A reduces uncertainty and increases all stakeholders' commitment to the success of the deal (Aguilera \& Dencker, 2004; Allatta \& Singh, 2011). Papadakis (2005) investigated the factors that 
influence the success of M\&A and found that communication and the formalization of the decision-making process were central to M\&A success. M\&A comes with some form of change in the acquirer's business and corporate structure, management and even changes in personnel. Employees and other stakeholders need to be adequately informed about how these changes affect the organization and their interest.

Once the key stakeholders have a buy-in, their commitment to achieving success becomes total. Conversely, ineffective communication increases the level of uncertainty, job insecurity, and reduces trust all of which impacts the organization negatively (Angwin et al., 2016). Ineffective communication can be adduced as the reason for the failure of the DaimlerBenz and Chrysler deal examined earlier which led many of the top executives and personnel to exit the Daimler-Benz after the deal. Therefore, communication is an essential factor in M\&A because it helps to engender stakeholder commitment to strategy and has a positive impact on employees who are the drivers of the outcomes.

Importantly, it should be noted that the characteristics identified above do not guarantee success when used on a standalone basis. The overarching intention of the acquirer needs to be reviewed alongside the performance of the new company post-acquisition to determine whether the acquisition is achieving its purpose. The acquisition of LinkedIn by Microsoft makes this clearer that organizations undertake M\&A deals for varied reasons which could be strategic or financially motivated implying that concerns about APP or making related acquisitions might be subordinated to the overarching objective.

Similarly, the features presented above might not necessarily be required. For instance, if an acquisition is made to gain patronage or to establish business relationship with government, the acquisition might not make sense to observers but if the firm can leverage the relationship to secure deals even unrelated to the acquisition made, how is one to assess the success of such M\&A? Therefore, it is my submission that the acquirer's objective and the post-acquisition performance should be evaluated to determine the success of the M\&A.

\section{Challenges of $\mathbf{M \& A}$}

The thorniest challenge in M\&A remains that of establishing the target firm's value which essentially is about understanding the difference between the worth of the asset and how much the acquirer should pay. Valuing the innovative potential of High-tech startups, for instance, presents significant valuation challenges because of the expectation gap and inability to access relevant data about the operations of the startup (Okafor, 2018). Additionally, 
issues of establishing the value of intangibles such as the value of management and employees require valuation artistry to resolve.

Inability to divorce or marry strategic and financial reasons during M\&A is another challenge encountered in the M\&A process (Merger Market, 2017). For instance, Microsoft's \$25.5bn acquisition of LinkedIn in 2016 was more of a strategic decision than a financial decision because Microsoft was intent on recreating a connective tissue for enterprises by embedding LinkedIn and Skype with its email system (Feller, 2016). There are also concerns about leadership and their ability to see through the strategy to achieve the desired synergy. Maintaining the existing workforce and putting succession plans in place could pose another challenge for M\&A success. Therefore, not correctly understanding how to handle these variables remains a significant challenge with M\&A.

\section{Improving M\&A Success Rate}

Improving the success rate of $\mathrm{M} \& \mathrm{~A}$ requires a thorough assessment of the purpose of the deal and examining whether it aligns with the acquirer's corporate strategy. Next, performing due diligence on the target firm to ensure all areas of concern are adequately identified beforehand and appropriate measures if required taken to address such concerns. Organizations seeking M\&A deals need to understand the importance of timing and early positioning during M\&A cycle to improve the chances of making cheaper acquisitions and synergy realization. Focusing on the industries where the acquirer has a competitive advantage and prior M\&A experience could improve the chances of M\&A success. The importance of having timely and consistent communication with relevant stakeholders cannot also be overemphasized.

\section{Conclusion}

Growth pursuit has been the primary objective for organizations involved in M\&A. In this paper, I reviewed the features of successful M\&A, the processes involved and why organizations go into M\&A. Besides the characteristics identified in the study, I proposed assessing the overarching intention of the acquirer alongside the post-acquisition performance of the new company to determine the M\&A success. Challenges facing M\&A were also discussed and ways of improving the success rate of M\&A accentuated.

\section{References:}

1. Abbott, A. (2000). Merger of Glaxo Wellcome and SmithKline Beecham creates pharmaceutical giant. Nature, 403, 232. doi:10.1038/35002148 
2. Access Bank. (2013). Access Bank annual report. Retrieved from https://nigerianelite.blob.core.windows.net/stocks/Access \%20Bank\% 20Annual\%20Report\%202013.pdf

3. Aderinokun, K., \& Chima, O. (2011). Ecobank targets Oceanic for retail banking expansion. Retrieved from https://www.proshareng.com/admin/upload/reports/EcobankTargetsO ceanicforRetailBankingExpansion.pdf

4. Aguilera, R., \& Dencker, J. (2004). The role of human resource management in cross-border mergers and acquisitions. The International Journal of Human Resource Management, , 15, 13551370 .

5. Alexandridis, G., Mavrovitis, C. F., \& Travlos, N. G. (2012). How have M\&As changed? Evidence from the sixth merger wave. The European Journal of Finance, 18(8), 663-688.

6. Allatta, J. T., \& Singh, H. (2011). Evolving communication patterns in response to an acquisition event. Strategic Management Journal, 32, 1099- 1118.

7. Andrade, G., Mitchell, M., \& Stafford, E. (2001). New evidence and perspectives on mergers. Journal of Economic Perspectives, 15(2), 103-120.

8. Angwin, D. N., Mellahi, K., Gomes, E., \& Peter, E. (2016). How communication approaches impact mergers and acquisitions outcomes. The International Journal of Human Resource Management, 27(20), 2370-2397. doi:10.1080/09585192.2014.985330

9. Arora, M., \& Kumar, A. (2012). A study on mergers and acquisitions: Its impact on management and employees. Research Journal of Economics and Business Studies, 1(5), 30-34. Retrieved from www.theinternationaljournal.org

10. Becketti, S. (1986). Corporate mergers and the business cycle. Economic Review, 71, 13-26.

11. Beckman, C. M., \& Haunschild, P. R. (2002). Network learning: The effects of partners' heterogeneity of experience on corporate acquisitions. Administrative Science Quarterly, 47(1), 92-124.

12. Beena, P. L. (2014). Mergers and acquisitions: India under globalization. The Journal for Decision Makers, 30(3), 392-394. doi:10.1177/0256090915600298

13. Benson, M. D., \& Shippy, J. S. (2013). The M\&A buy side process: An overview for acquiring companies. Stout Journal, 1-8.

14. Bhide, A. (1990). Reversing corporate diversification. Journal of Applied Corporate Finance, 3(2), 70- 81. 
15. Brearley, B. (2013). Can Old Mutual Global Investors become a top 5 player in the UK? Retrieved from https://www.fundstrategy.co.uk/issues/online-february-2013/can-oldmutual-global-investors-become-a-top-5-player-in-the-uk/

16. Carroll, P., \& Mui, C. (2009). Billion dollar lessons: What you can learn from the most inexcusable business failures of the last 25 years. New York, NY: Portfolio.

17. Cartwright, S., \& Schoenberg, R. (2006). Thirty years of mergers and acquisitions research: Recent advances and future opportunities. British Academy of management, 17(1), 1-5. doi:10.1111/j.14678551.2006.00475.x

18. Ceil, C. (2013). Role of due diligence in mergers and acquisitions. Social Science Research Network, 1-7. doi:10.2139/ssrn.2294836

19. Chemla, G., \& Chemla, G. (2003). Downstream competition, foreclosure and vertical integration. Journal of Economics and Management Strategy, 12(2), 261-289.

20. Ciobanu, R. (2015). Mergers and acquisitions: Does the legal origin matter? Procedia Economics and Finance, 32, 1236-1247. doi:10.1016/S2212-5671(15)01501-4

21. Clark, P., \& Mills, R. W. (2013). Masterminding the deal: Breakthroughs in M\&A strategy and analysis. London, England: Pondbridge.

22. Copeland, T. E., Weston, J. F., \& Kuldeep, S. (2004). Financial theory and corporate policy. New Jersey, NJ: Prentice Hall.

23. Cordeiro, M. (2014). The seventh M\&A wave. Retrieved from https://camayapartners.com/wp-content/uploads/2016/06/Theseventh-MA-wave.pdf

24. Cording, M., Christmann, P., \& Bourgeois, L. J. (2002). A focus on resources in M\&A success: A literature review and research agenda to resolve two paradoxes. Academy of Management, 1-40.

25. Covin, G. (2003). Time Warner, don't blame Steve case. Fortune, 147(2), 35 .

26. Datta, D. K., Pinches, G. E., \& Narayanan, V. K. (1992). Factors influencing wealth creation from mergers and acquisitions: A metaanalysis. Strategic Management Journal, 13, 67- 84.

27. Denison, D. R., \& Ko, I. (2016). Cultural due diligence in mergers and acquisitions Volume. Advances in Mergers and Acquisitions, 15, 53 72. doi:10.1108/S1479-361X20160000015004

28. Feller, G. (2016). This is the real reason Microsoft bought LinkedIn. Retrieved from https://www.forbes.com/sites/grantfeller/2016/06/14/this-is-the-realreason-microsoft-bought-linkedin/\#6bb3a6fdf04a 
29. Ficery, K., Herd, T., \& Pursche, B. (2007). Where has all the synergy gone? The M\&A puzzle. Journal of Business Strategy, 28(5), 29-35. doi:10.1108/02756660710820802

30. French, J. (2018). Why M\&A due diligence is so important: A cautionary tale. Retrieved from https://www.startups.co/articles/importance-of-merger-acquisitiondue-diligence

31. Friedman, Y., Carmeli, A., Tishler, A., \& Shimizu, K. (2016). Untangling micro-behavioral sources of failure in mergers and acquisitions: A theoretical integration and extension. The International Journal of Human Resource Management, 27(20), 2339-2369.

32. Garzella, S., \&Fiorentino, R. (2014). A synergy measurement model to support the pre-deal decision making in mergers and acquisitions. Journal of Management History, 52(6), 1194-1216. doi: 10.1108/MD10-2013-0516

33. Gaughan, P. A. (2002). What's the outlook for M\&A in an uncertain market? Journal of Corporate Accounting \& Finance, 13(5), 51-53. doi:10.1002/jcaf.10087

34. Ghaur, A. A. (2017). Impact of domestic M\&A on acquirer shareholder's equity: Evidence from Oslo Stock Exchange. Norwegian University of Life Sciences, 1-35. Retrieved from https://brage.bibsys.no/xmlui/bitstream/handle/11250/2461257/Abrar $\% 20$ Ghauri.pdf?sequence $=1$

35. Grave, K., Vardiabasis, D., \& Yavas, B. (2012). The global financial crisis and M\&A. International Journal of Business and Management, 7(11), 56-66. doi:10.5539/ijbm.v7n11p56

36. Haleblian, J., \& Finkelstein, S. (1999). The influence of organizational acquisition experience on acquisition performance: A behavioral learning perspective. Administrative Science Quarterly, 44, 29-56.

37. Hitt, M. A., King, D. R., Krishnan, H., Makri, M., \& Schijven, M. (2012). Creating value through mergers and acquisitions: Challenges and opportunities. Management Faculty Research and Publications, 163. Retrieved from https://epublications.marquette.edu/cgi/viewcontent.cgi?referer=https $: / /$ www.google.com.ng/\&httpsredir $=1 \&$ article $=1123 \&$ context $=$ mgmt fac

38. Hoang, T. V., \& Lapumnuaypon, K. (2007). Critical success factors in merger \& acquisition: Projects A study from the perspectives of advisory firms, Retrieved from http://www.divaportal.org/smash/get/diva2:141248/fulltext01.pdf 
39. Houwers, R. (2016). M\&A and failure factors. Master Thesis University of Twente, 1-153. Retrieved from https://essay.utwente.nl/70883/1/MASTER\%20THESIS.pdf

40. Iankova, S. (2014). Main factors of success in mergers and acquisitions' performance. Sofia University Faculty of Economics and Business Administration, 12, 373-389.

41. Ikhwan, M., \& Haeruddin, M. (2017). Mergers and acquisitions: Quo vadis? Management, 7(2), 84-88. doi:10.5923/j.mm.20170702.02

42. Jagersma, P. K. (2005). Cross-border alliances: Advice from the executive suite. Journal of Business Strategy, 26(1), 41-50. doi:10.1108/02756660510575041

43. Jewoo, K., \& Tianshu, Z. (2014). A review of merger and acquisition wave literature: Proposing future research in the restaurant industry. Hospitality Review, 31(3), 94-117.

44. Junior, P. R., Pamplona, E. O., \& Francisco- da-Silva, A. (2013). Mergers and acquisitions: An efficiency evaluation. Applied Mathematics, 4, 1583-1589.doi: 10.4236/am.2013.411213

45. Laamanen, T. (2007). On the role of acquisition premium in acquisition research. Strategic Management Journal, 28, 1359-1369.

46. Lamoreaux, N. R. (1985). The great merger movement in American business. Cambridge, United Kingdom: Cambridge University Press.

47. Lieberman, M., \& Montgomery, D. (1988). First-mover advantages. Strategic Management Journal, 9, 41-58.

48. Malik, F., Anuar, M. A., Khan, S., \& Khan, F. (2014). Mergers and acquisitions: A conceptual review. International Journal of Accounting and Financial Reporting, 4(2), 520-533. doi:10.5296/ijafr.v4i2.6623

49. Marques-Ibanez, D., \& Altunbas, Y. (2004). Mergers and acquisitions and bank performance in Europe: The role of strategic similarities. ECB Working Paper Series No 398, 1-37.

50. Martin, R. L. (2016). M\&A: The one thing you need to get right. Harvard Business Review, 42-48. Retrieved from https://hbr.org/2016/06/ma-the-one-thing-you-need-to-get-right

51. Martynova, M. V., \& Renneboog, L. (2008). A century of corporate takeovers: What have we learned and where do we stand? Journal of Banking \& Finance, 32(10), 2148-2177.

52. Matsusaka, J. G. (1993). Target profits and managerial discipline during the conglomerate merger wave. The Journal of Industrial Economics, 41(2), 179-189.

53. McGeehan, P., \& Sorkin, A. R. (2000). Chase Manhattan to acquire J.P. Morgan for $\$ 30.9$ billion. New York Times. Retrieved from 
https://archive.nytimes.com/www.nytimes.com/learning/teachers/feat ured_articles/20000914thursday.html

54. Merger Market. (2017). M\&A valuation: Trends, challenges and horror stories. Retrieved from https://www.mergermarket.com/assets/Firmex_Q3\%202017_Newslet ter_Final_0.pdf

55. Motis, J. (2007). Mergers and acquisitions motives. Toulouse School of Economics, 1-31. Retrieved from https://economics.soc.uoc.gr/wpa/docs/paper2mottis.pdf

56. Okafor, A. (2018). Impact of valuation methods on the likelihood of mergers and acquisitions of high-tech startups companies in Nigeria (Doctoral dissertation). Available from ProQuest Digital Dissertations and Theses database. (UMI No. 10828378)

57. Olusola, O. A., \& Ojenike, J. O. (2012). Mergers and performance of conglomerates companies in Nigeria. Journal of Emerging Trends in Economics and Management Sciences, 3(4), 393-397.

58. Pamplona, E. O., \&Junio, P. R. (2013).Analysis of mergers and acquisitions in Brazilian companies. African Journal of Business Management, 7(26), 2625-2633. doi:10.5897/AJBM2013.4815

59. Papadakis, V. M. (2005). The role of broader context and the communication program in merger and acquisition implementation success. Management Decision, 43(2), 236-255. doi:10.1108/00251740510581948

60. Piesse, J., Lee, C. F., Lin, C., \& Kuo, H. C. (2013). Merger and acquisition: Definitions, motives, and market responses. Encyclopedia of Finance, 411-420. doi:10.1007\%2F978-1-4614-5360-4_28

61. Refsnes, F. O. (2012). What explains mergers' success or failure? The role of organizational structures, strategies and external environments in mergers. The European Inter-University Association on Society, Science and Technology, 1-103. Retrieved from www.esst.uio.no

62. Rock, K. (1986). Why new issues are underpriced? Journal of Financial Economics, 15, 187-212.

63. Ross, S. A., Westerfield, R. W., \& Jaffe, J. (2010). Corporate finance (9th ed.). New York, NY: McGraw-Hill/Irwin.

64. Ruess, M., \&Voelpel, S. C. (2012). The PMI scorecard: A tool for successfully balancing the post-merger integration process. Organizational Dynamics, 41, 78-84. doi: 10.1016/j.orgdyn.2011.12.010

65. Sankar, B. P. (2018). Payment methods in mergers and acquisitions: A theoretical framework. International Journal of Accounting and Financial Reporting, 8(1), 170-187. doi:10.5296/ijafr.v8i1.12354 
66. Schmidt, B. (2015). Costs and benefits of friendly boards during mergers and acquisitions. Journal of Financial Economics, 117(2), 424-447.

67. Seth, A. (1990). Sources of value creation in acquisitions: An empirical investigation. Strategic Management Journal, 11, 431-447.

68. Shleifer, A., \& Vishny, R. W. (1991). Takeovers in the '60s and the '80s: Evidence and implications. Strategic Management Journal, (12), 51-59.

69. Sikora, M. (2001). 2000 M\&A profile. Mergers \& Acquisitions, 36, 23.

70. Singh, H., \& Montgomery, C. A. (1987). Corporate acquisition strategies and economic performance. Strategic Management Journal, 8, 377-387.

71. Sirower, M. L. (1997). The synergy trap: How companies lose the acquisition game. New York, NY: The Free Press.

72. Smirnova, Y. V. (2014). Economics questions, issues and problems, motives for mergers and acquisitions in the banking sector of Kazakhstan. Suleyman Demirel University Research, 79-98. Retrieved from

http://www.irisro.org/economics2014january/21YelenaSmirnova.pdf

73. Stigler, G. J. (1950). Monopoly and oligopoly by merger. The American Economic Review, 40(2), 23- 34.

74. Thomson Reuters. (2017). Mergers \& acquisitions review financial advisory review - Full year 2016. Retrieved from http://share.thomsonreuters. com/general/PR/MA_4Q_2016_E.pdf

75. Verma, N., \& Sharma, R. (2014). Impact of mergers \& acquisitions on firms' long term performance: A pre \& post analysis of the Indian telecom industry. International Journal of Research in Management \& Technology, 4(1), 11-19. Retrieved from http://www.iracst.org/ijrmt/

76. Vretenar, N., Sokolic, D., \& Mrak, M. K. (2017). Motives for mergers and acquisitions in small and medium-sized enterprises. International Multidisciplinary Scientific Conferences on Social Sciences and Arts, 4, 689-696. doi:10.5593/sgemsocial2017/15/S05.087

77. Westbrock, B. (2004). Horizontal integration in markets for complementary components and vertical product differentiation: A case-based analysis in the semiconductor industry. University of Manheim Discussion Paper Series 05-05.

78. Yagil, J. (1996). Mergers and macro-economic factors. Review of Financial Economics, 5(2), 181-190. 